Guilda de visitantes de nectários extraflorais de Ipomoea carnea subsp. fistulosa (Convolvulaceae) em uma área de semiárido antropizado da Bahia, Brasil ${ }^{1}$

\author{
Extrafloral nectaries visitor guild of \\ Ipomoea fistulosa (Convolvulaceae) in a semi-arid \\ antropized area of Bahia, Brazil ${ }^{1}$
Joicelene Regina Lima da PaZ ${ }^{1,2}$
Clarissa Cunha Santana ${ }^{3}$, Wagner Pereira Silva ${ }^{2}$ Mônica Costa de Abreu ${ }^{4}$
\& Camila Magalhães Pigozzo 5

Os nectários extraflorais (NEFs) são glândulas secretoras que embora possam estar próximos às estruturas reprodutivas das plantas não estão associados diretamente ao processo de polinização (Fiala \& MASCHWITZ, 1991). Podem ser encontrados em todas as partes aéreas das angiospermas, especialmente nas folhas, podendo ser ativas ou não (BENTLEY, 1977) e exibir morfologia e estrutura anatômica variável.

Os nectários extraflorais são amplamente distribuídos nas regiões tropicais e temperadas em vários grupos de vegetais (OliveIRA \& PIE, 1998), com ocorrência em mais de 2200 espécies de 330 gêneros (em cerca de 90 famílias) (KopTuR, 1992).

${ }^{1}$ Parte da dissertação da primeira autora. ${ }^{2}$ Laboratório de Entomologia, Depto Ciências Biológicas, Univ. Estadual Feira de Santana - Av. Universitária, s/n, Cidade Universitária, Cep 44031-460, Feira de Santana, BA, Brasil — joicelene.lima@yahoo.com.br (para correspondência), wagner.sillva@yahoo.com.br. ${ }^{3}$ Lab. Biol. Parasitária, Centro de Pesquisas Gonçalo Moniz, Fundação Oswaldo Cruz (Fiocruz) - Rua Waldemar Falcão, s/n, Candeal,

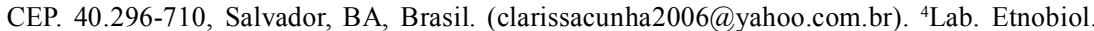
Etnoecol., Depto de Ciências Biológicas, Univ. Estadual Feira de Santana - Av. Universitária, s/n, Cidade Universitária, Cep 44031-460, Feira de Santana, BA, Brasil. (monika.abreu@yahoo.com.br). ${ }^{5}$ Coordenadora dos Cursos de Licenciatura e Bacharelado em Ciências Biol. Centro Universitário Jorge Amado (UNIJORGE) - Av. Luiz Viana Filho, Paralela,Cep 41745-130 Salvador, BA, Brasil. (camilapigozzo@gmail.com). 
Em Convolvulaceae, a ocorrência de estruturas extraflorais está concentrada no gênero Ipomoea, com os NEFs localizados principalmente em folhas e/ou na base das flores, como em Ipomoea carnea subsp. fistulosa (Mart. ex Choisy) D.F. Austin. Esta é uma espécie nativa, perene e resistente a longos períodos de seca (HoEHNE, 1939 apud GotaRdo, 2009), e muito comum em ambientes abertos, como na Caatinga.

A presença de nectários extraflorais em convolvuláceas as tornam atrativas às visitas de diferentes grupos de insetos (KeELER, 1975; KeELER, 1977; Keeler, 1978; Keeler, 1980; Beckmann Jr. \& Stucky, 1981; Keeler \& Kaul, 1984; Fidalgo, 1997; Blüthger \& ReIfEnRath, 2003; Mondal et al., 2013). Ecologicamente, a funcionalidade dessas glândulas está associada ao fornecimento de substâncias nutritivas. Em contrapartida, os visitantes atuam na proteção contra herbívoros, como acontece em várias plantas trepadeiras, aumentando as chances de fitness reprodutivo temporalmente (ver JANZEN, 1966).

As formigas são frequentemente associadas aos NEFs, seja em busca de alimentos (Oliveira, 1997; Oliveira \& Pie, 1998; Charão, 2005; KNOECHELMANN \& MoRAIS, 2008) ou como protetores contra a herbivoria (Blüthgen et al., 2000; Madureira \& Sobrinho, 2002; DÁttilo et al., 2009). Na maioria dos casos, o comportamento predatório e a agressividade destes insetos reduzem o nível de danos causados nas plantas pelos herbívoros mas, em outros casos, esta relação ainda não está bem elucidada (SChultz \& MCGLYNN, 2000; Cogni et al., 2003).

Os NEFs podem ser considerados mediadores da interação plantaanimal (KopTUR, 1992). É de se supor que variações espaciais e temporais estejam relacionadas com os efeitos dos visitantes às plantas com nectários extraflorais e que o forrageamento nas flores seja otimizado, direta ou indiretamente.

Neste trabalho inventaria-se a guilda de visitantes de nectários extraflorais em Ipomoea carnea subsp. fistulosa, com ênfase nas variações temporais e no comportamento de coleta relacionado com aspectos fenológicos do vegetal em uma área antropizada do semiárido baiano.

\section{MATERIALE MÉTODOS}

O estudo foi realizado no campus da Universidade Estadual de Feira de Santana (UEFS) (12¹2'10”S, 38 58'15”W), no município de Feira de Santana, Bahia, Nordeste do Brasil. O clima local é definido como seco/subúmido, com temperatura média anual em torno de $24^{\circ} \mathrm{C}$ e pluviosidade aproximada de $848 \mathrm{~mm}$ anuais (Diniz et al., 2008). Os dados meteorológicos do período de estudo foram obtidos na Estação 
Climatológica da UEFS (Fig. 1). A Caatinga é a vegetação original da área mas atualmente apresenta marcante ação antrópica (LEAL et al., 2003).

Indivíduos floridos de Ipomoea carnea subsp. fistulosa $(\mathrm{n}=17$ marcados) estavam dispostos às margens de uma estrada acessória da UEFS, em uma área de $90 \times 10 \mathrm{~m}^{2}$. Os vouchers botânicos encontramse tombados no Herbário da Universidade Estadual de Feira de Santana (HUEFS 159.601) e no Herbário Maria Eneyda P. Kauffmann (SP 420.333).

As coletas e observações em NEFs foram realizadas por dois pesquisadores mensalmente, durante três dias consecutivos, entre maio e agosto de 2010. Aspectos da biologia floral de I. carnea subsp. fistulosa também foram investigados. A contagem de flores abertas foi realizada mensalmente, durante os dias em campo, em três períodos distintos: pela manhã (6:00 h), tarde (14:00 h) e noite (19:00 h). O tamanho das flores foi classificado de acordo com as categorias de MACHADO \& LOPES (2004).

Os visitantes de NEFs foram coletados nos dois primeiros dias através do método de busca ativa, utilizando redes entomológicas e pinças, em dois espécimes floridos. Sendo o terceiro dia reservado apenas para observações do comportamento dos insetos e contagem do número e duração das visitas.

As atividades em campo foram desenvolvidas das 5 às 18 horas (do nascer ao pôr-do-sol) durante 30 minutos, a cada hora observada, em dois indivíduos floridos. Coletas e observações complementares no período

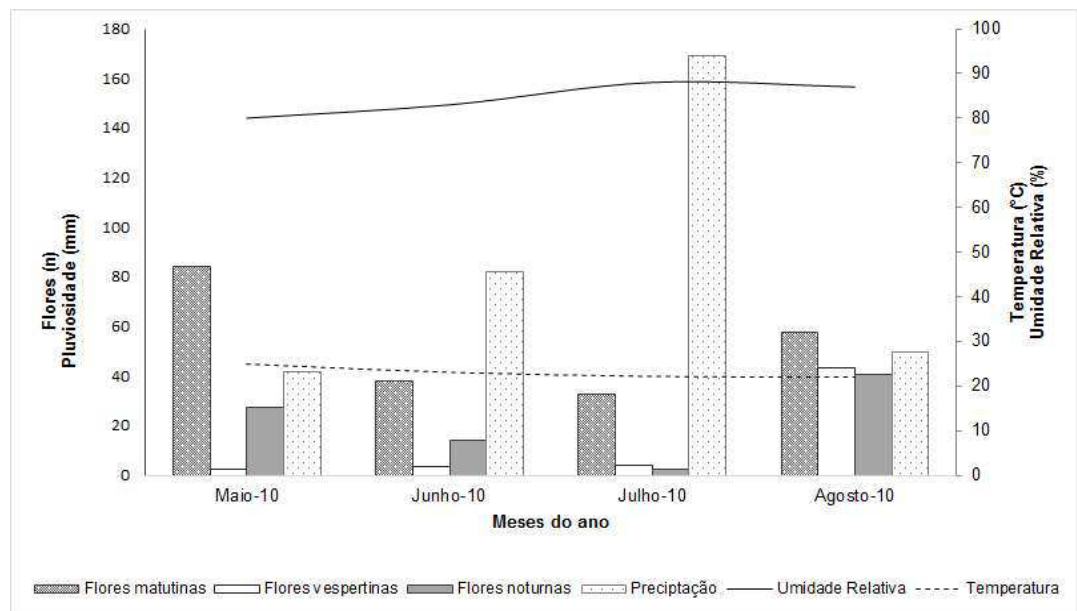

Fig. 1. Flores de Ipomoea carnea subsp. fistulosa (Convolvulaceae) e dados macrometeorológicos em Feira de Santana (BA), Brasil, entre maio e agosto de 2010. 
noturno (das 18 às 5 horas) foram realizadas nos meses de junho e agosto de 2010, totalizando108 horas de observação ( 48 horas de coletas diurnas, 24 horas de coletas noturnas, 24 horas de observações diurnas e 12 horas noturnas).

O comportamento de forrageio dos visitantes foi descrito através de observações visuais diretas, vídeos e fotografias. Para as análises das atividades diárias foi considerado apenas o número de visitas das espécies mais abundantes e constantes aos NEFs. Algumas espécies de difícil identificação nas flores foram consideradas em nível de família, como os representantes dos Halictidae, por exemplo.

Para a classificação do porte corpóreo dos visitantes utilizou-se as categorias adaptadas de VIANA \& KLEINERT (2005). A constância (C) das espécies visitantes foi avaliada e categorizadas de acordo com THOMAZINI \& Thomazini (2002). Os visitantes testemunhos foram depositados no Museu de Zoologia da Universidade Estadual de Feira de Santana (MZFS).

Os dados meteorológicos (temperatura, umidade relativa e intensidade luminosa) foram mensurados em intervalos de 30 minutos, a cada hora, durante todas as atividades em campo. Para a análise entre o número de flores abertas e números de visitantes coletados, assim como entre o número de visitantes coletados e os fatores meteorológicos, utilizou-se o teste de correlação de Spearman, no programa IBM ${ }^{\circledR}$ SPSS ${ }^{\circledR}$ Statistics 20.0 for Windows, com a correção por Bonferroni $(p<0.01)$. A normalidade dos dados foi testada através do teste de KolmogorovSmirnov $(p<0.05)$, no programa IBM ${ }^{\circledR}$ SPSS ${ }^{\circledR}$ Statistics 20.0 for Windows (MaGuRRAN, 2003).

\section{RESULTADOS}

Ipomoea carnea subsp. fistulosa apresenta nectários extraflorais na extremidade distal do pecíolo das folhas, em ambos os lados (Fig. 2A). Assim como, outras cinco glândulas secretoras de néctar margeando a base das flores (pedúnculo), ativos também em botões florais e em frutos em início de maturação (Fig. 2 C).

Os NEFs da planta em estudo continuaram ativos mesmo após a queda da corola até o início do desenvolvimento dos frutos, atraindo muitos visitantes. Aparentemente a secreção de néctar extrafloral ocorre durante $24 \mathrm{~h}$, em virtude do acúmulo de secreção de gosto adocicado na base dos NEFs (Fig. 2 B e 2 D), inclusive à noite, bem como pela visitação frequente dos insetos às glândulas durante dia e noite (Fig. 3).

A presença de flores em I. carnea subsp. fistulosa ocorreu durante todos os meses de observação, com variação do número de flores ao longo dos meses e do dia. Ao longo de um dia, o mesmo indivíduo botânico 


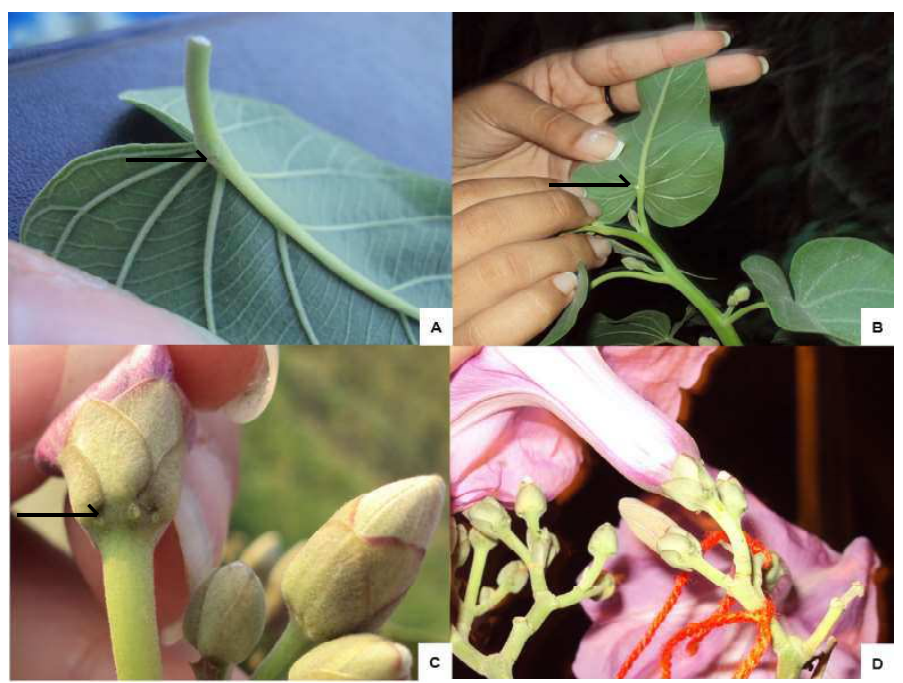

Fig. 2. Nectários extraflorais de Ipomoea carnea subsp. fistulosa (Convolvulaceae): A, um par lateral na extremidade distal do pecíolo, com destaque para a formação da gotícula de néctar durante à noite $(\mathrm{B}) ; \mathrm{C}$, cinco glândulas na base das sépalas, e acúmulo de secreção na base da flor no período noturno (D).

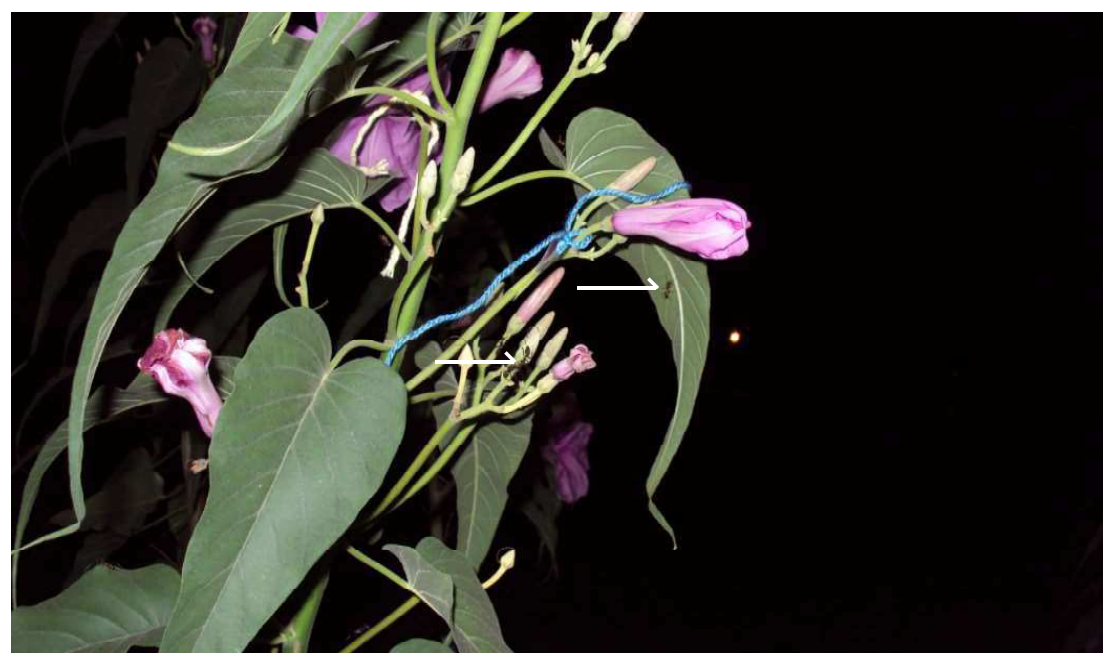

Fig. 3. Nectários extraflorais de Ipomoea carnea subsp. fistulosa (Convolvulaceae) sendo visitados durante o período noturno. Notar a presença de formigas (Ectatomma brunneum Smith, 1858 e Camponotus melanoticus Emery, 1894) nas folhas e no cálice de flores e botões. 
exibia três momentos de abertura de flores: manhã (4 horas), tarde (14 horas) e noite (19 horas), com longevidades distintas. Amaioria das flores exibiu antese matutina e noturna durante todos os meses observados, variando entre $n=35,5$ (julho-10) a $n=141,7$ (agosto-10) (Fig. 1).

A quantidade de flores no período de estudo não apresentou correlação significativa com qualquer parâmetro climático. No entanto, as flores matutinas apresentaram correlação negativa significativa com os valores de precipitação, de modo que a quantidade de flores abertas pela manhã foi inversamente proporcional ao volume de chuva $\left(\mathrm{r}^{2}=-1,0\right.$ e $\left.\mathrm{p}<0,01\right)$. Da mesma forma, as flores vespertinas apresentaram correlação negativa significativa, porém com os valores de temperatura, quando em temperaturas mais elevadas, o número de flores abertas no período da tarde foi menor.

No total, foram coletados 2602 indivíduos de insetos visitantes forrageando nos nectários extraflorais de I. carnea subsp. fistulosa, pertencentes a cinco ordens e distribuídos em 45 espécies (Tabela 1). Os representantes da ordem Hymenoptera foram os visitantes mais abundantes $(\mathrm{n}=1860)$, correspondendo a $71,5 \%$ do total, sendo que destes as formigas $(61,8 \%, \mathrm{n}=1610)$ foram predominantes, seguido das vespas aculeata $(6,5 \%, \mathrm{n}=168)$ e abelhas $(3,2 \%, \mathrm{n}=82)$. A ordem Diptera também contou com muitos representantes $(n=731$, e $28,1 \%$ do total), e em conjunto com os himenópteros representaram $99,6 \%$ da totalidade dos visitantes coletados nas glândulas extraflorais. Coleoptera $(\mathrm{n}=9$, e $0,36 \%)$ e Lepidoptera $(\mathrm{n}=1$, e $0,04 \%)$ foram as ordens menos representativas (Tabela. 1).

As famílias e subfamílias que se destacaram pelo maior número de indivíduos coletados foram: Dolichoderinae (Formicidae) $(\mathrm{n}=756),(\mathrm{n}=$ 635), Formicinae (Formicidae) $(\mathrm{n}=520)$, Ectatomminae (Formicidae) ( $=265)$ e Vespidae $(n=160)$ (Tabela 1$)$. Considerando a riqueza de espécies, os dípteros (13 espécies), formigas (11 espécies) e vespas aculeata (10 espécies) foram os grupos de insetos mais diversos, enquanto besouros e borboletas exibiram poucas espécies, cinco e uma, respectivamente (Tabela 1).

As espécies Dorymyrmex biconis Forel, $1912(\mathrm{n}=748)$, Sarcophaga sp. $(\mathrm{n}=635)$, Ectatomma brunneum Smith, $1858(\mathrm{n}=265)$ e Camponotus melanoticus Emery, $1894(\mathrm{n}=199)$ foram os insetos mais frequentes visitantes em nectários extraflorais de I. carnea subsp. fistulosa, e representam juntas $71 \%$ de todos os indivíduos coletados. No que se refere à constância das espécies, 48,9\% dos insetos que frequentaram os NEFs da planta em estudo foram considerados constantes, enquanto as demais foram consideradas ocasionais $(29,8 \%)$ ou acessórias $(21,3$ $\%$ ) (Tabela 1). 
Acta Biol. Par., Curitiba, 45 (1-2): 21-51. 2016.

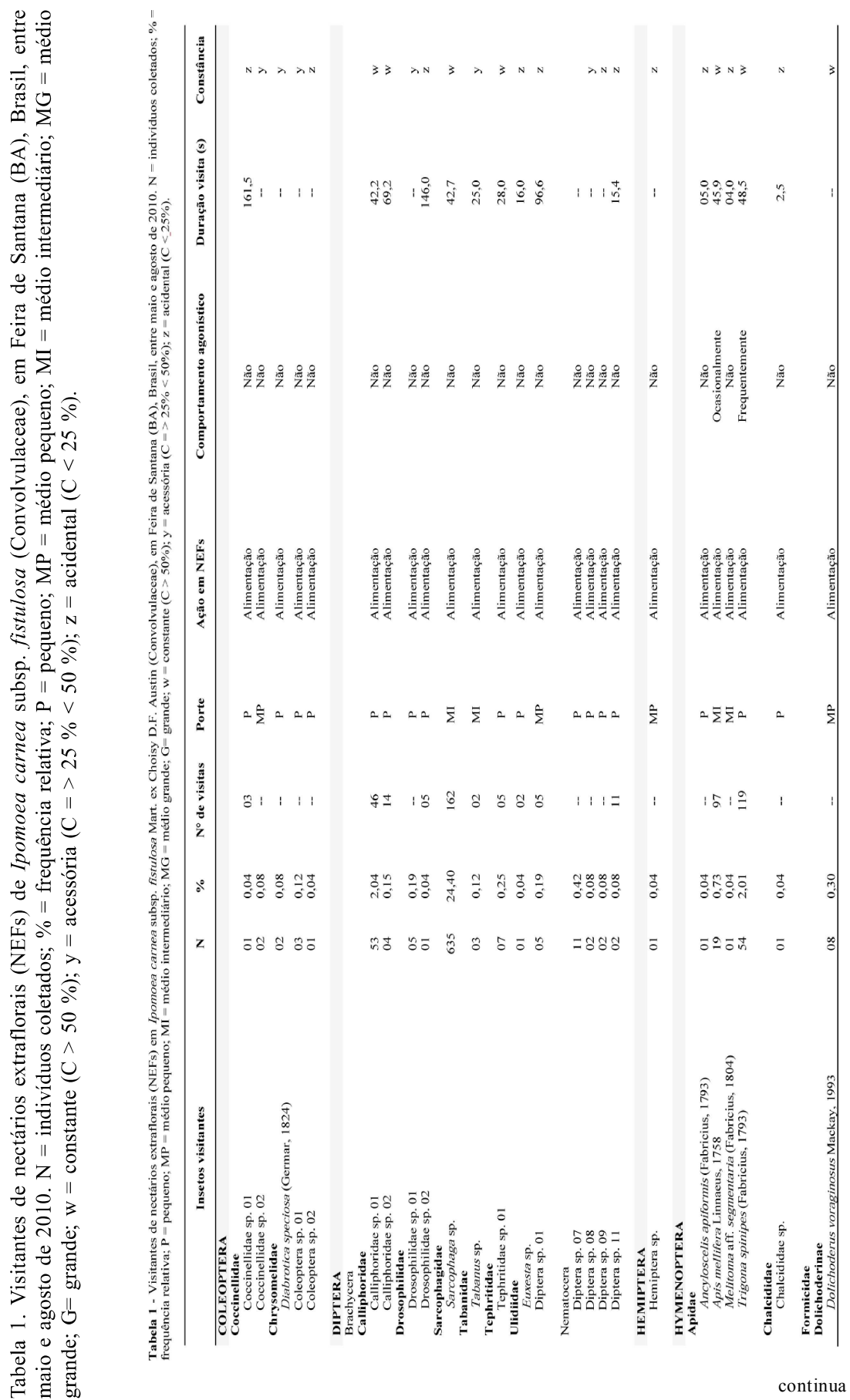




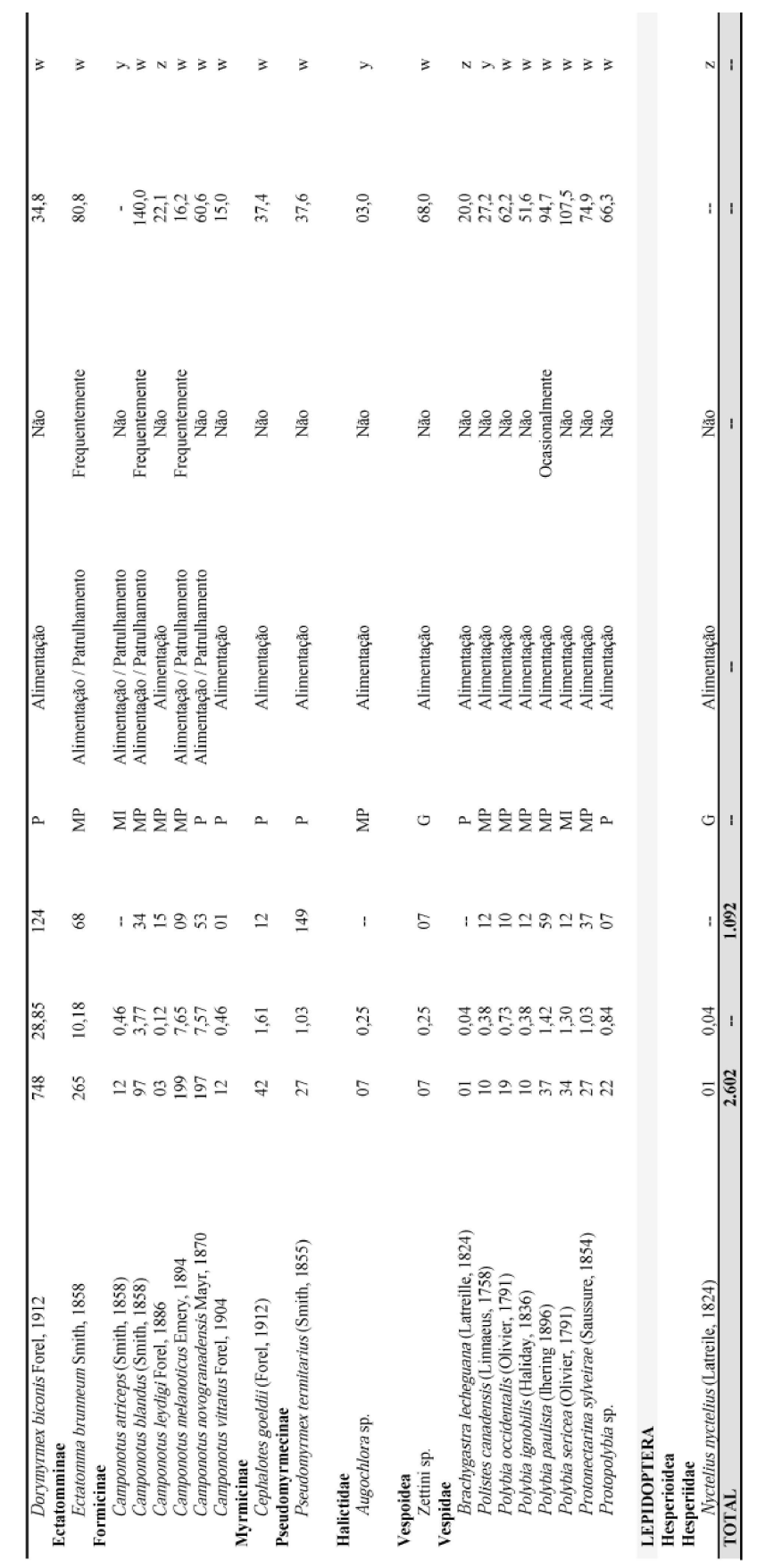


Durante os meses de observação, os visitantes forragearam ativamente nos NEFs de $I$. carnea subsp. fistulosa. O maior número de visitantes foi registrado no mês de agosto-10 $(\mathrm{n}=842)$ e a menor abundância foi registrada em julho-10 $(n=412)$, coincidindo com o maior e menor número de flores abertas disponíveis mensais, respectivamente (Fig. 4 e 5). O total de flores apresentou correlação positiva e significativa com o total de insetos $\left(r^{2}=1,0\right.$ e $\left.p<0,01\right)$, de forma que quanto mais flores estavam disponíveis, mais insetos foram coletados forrageando nos nectários. No entanto, na análise por turno, nenhuma relação significativa entre flores e visitantes foi encontrada.

Ao longo de todas as 24 horas, houve atividade de forrageamento em NEFs de I. carnea subsp. fistulosa. Os insetos diurnos $(5: 00 \mathrm{~h}-17: 59$ h) $(n=2.303)$ foram os mais abundantes em todos os meses, com a exceção de junho-10, quando comparados com os visitantes noturnos $(18: 00 \mathrm{~h}-4: 59 \mathrm{~h})(\mathrm{n}=299)$, estes últimos representados em quase sua totalidade por formigas (Fig. 5). A abundância total de visitantes em NEFs, assim como quando analisada a quantidade por turnos, não exibiu relação significativa com os dados meteorológicos.

Os dípteros foram os visitantes de glândulas extraflorais mais abundantes em maio-10. Nos outros meses a maior incidência foi de formigas, seguido das vespas aculeatas, em menor proporção (Fig. 6). Em agosto-10, a maioria dos visitantes diurnos e noturnos foi representada pelas formigas. As abelhas apresentaram a sua maior representatividade neste mesmo mês (Fig. 6).

Em consideração à atividade diária dos insetos, durante todas as horas do dia houve atividade de forrageio para coleta de néctar em I. carnea subsp. fistulosa. Os Formicidae foram os principais visitantes ao longo de todas as horas do dia (Fig. 7A), com o maior número de indivíduos ativos entre 07:00 h e 16:00 h. Os Diptera estiveram ativos durante todo o período diurno, com a maioria dos representantes concentrando o forrageio entre 05:00 h e 16:00 h. As vespas aculeata estiveram ativas durante todas as horas no intervalo entre 05:00 h e 17:00 h. No entanto, as abelhas exibiram maior atividade de forrageio com visitas entre 07:00 he 11:00 h.

No gráfico de atividade diária das espécies mais constantes (Fig. 7B), a maior atividade foi entre 06:00 h e 16:00 h, correspondendo a 83,4 $\%$ de toda a amostragem. Entretanto, apenas as formigas estiveram ativas tanto durante o dia, quanto à noite. Enquanto as espécies dos demais insetos distribuíram as suas atividades durante o período diurno nos nectários. 


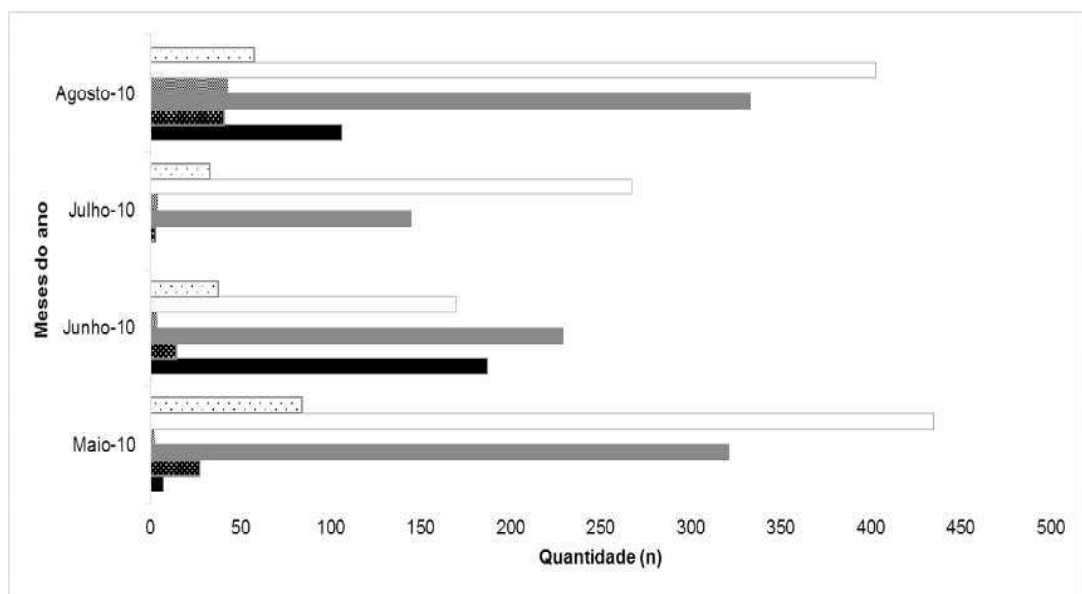

$\square$ Flores matutinas $\square$ Visitantes matutinos a Flores vespertinas $₫$ Visitantes vespertino \& Flores noturnas $\backsim$ Visitantes noturnos

Fig. 4. Número de flores e de visitantes de nectários extraflorais coletados em Ipomoea carnea subsp. fistulosa (Convolvulaceae) e dados meteorológicos em Feira de Santana (BA, Brasil) entre maio e agosto de 2010.

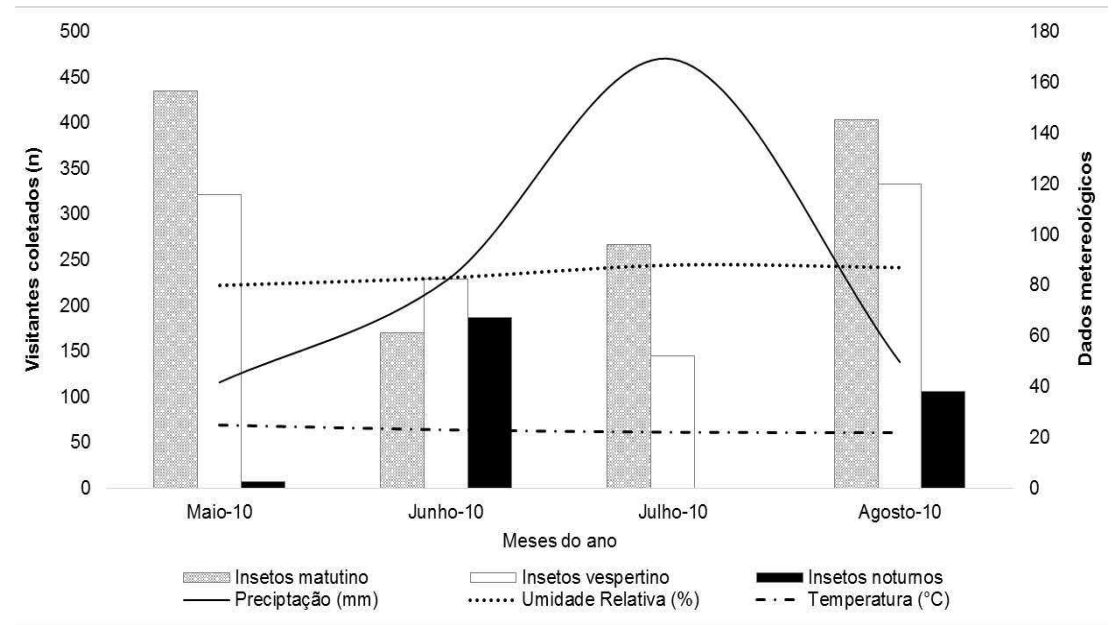

Fig. 5. Visitantes de nectários extraflorais coletados em Ipomoea carnea subsp. fistulosa (Convolvulaceae) e dados meteorológicos em Feira de Santana (BA, Brasil) entre maio e agosto de 2010 


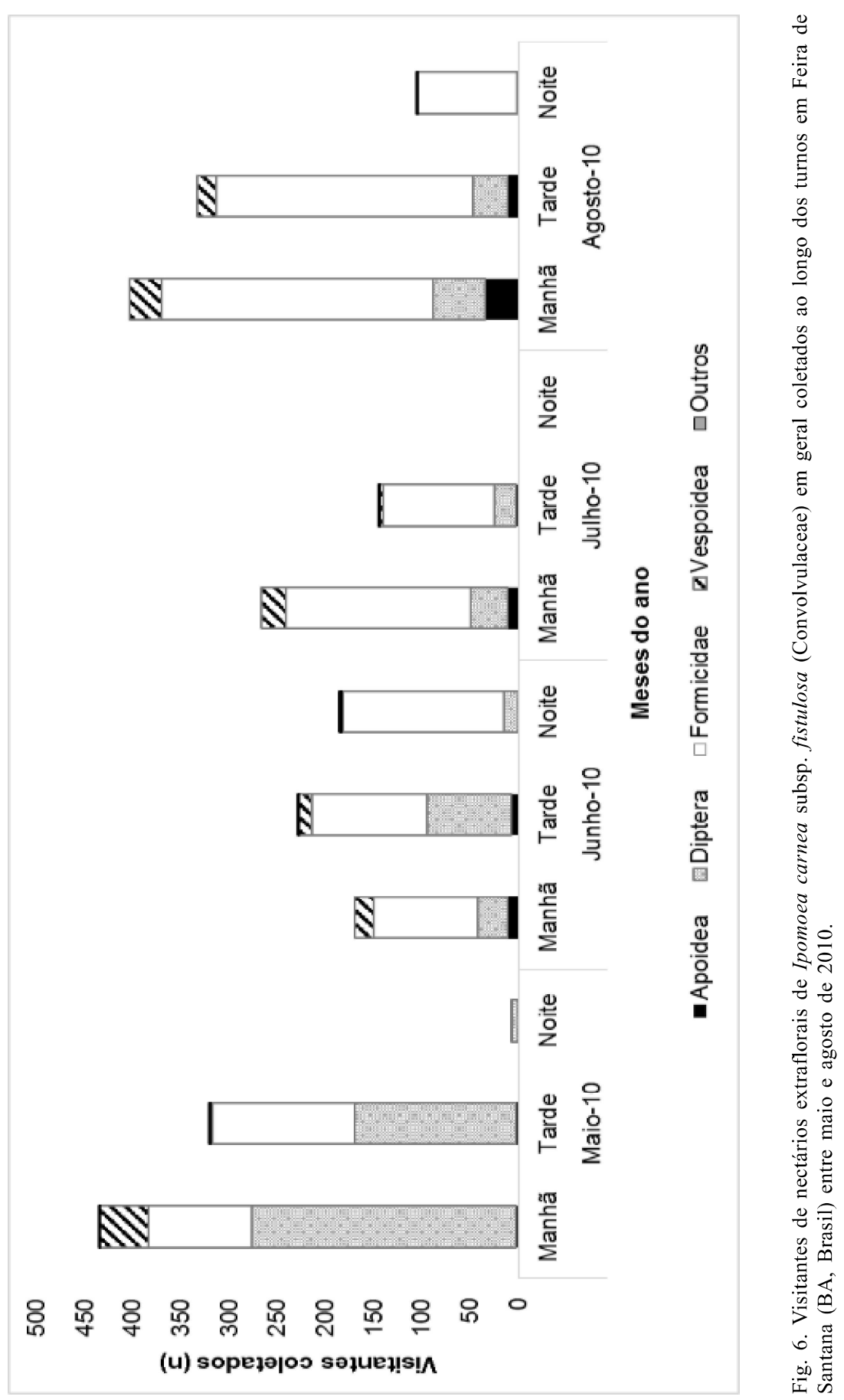


Quando considerada apenas o número de visitas (Fig. $8 \mathrm{~A}$ ), através da observação das atividades de forrageio dos insetos, também há predominância de formigas no período diurno. Sendo concentrada, de maneira generalizada entre os grupos, no intervalo entre 08:00 h e 18:00 h $(94,7 \%$ do total). Na contagem de visitas, ainda há predominância do abundante grupo das formigas. Mas, diferentemente do dos insetos coletados, apenas quando considerado o número de visitas há uma distribuição mais proporcional entre as horas do dia e os demais grupos de insetos visitantes, a saber: dípteros, vespas e abelhas (Fig. 8A).

Todavia, quando consideramos as espécies mais constantes da guilda visitante, a representatividade dos insetos retorna o destaque para Formicidae, especialmente Dorymyrmex biconis $(\mathrm{n}=124)$, Sarcophaga sp. $01(\mathrm{n}=162)$ e Trigona spinipes (Fabricius, 1793) $(\mathrm{n}=119)$. Essas três espécies juntas representam $63 \%$ da quantidade de visitas das espécies mais constantes, com atividades também distribuídas entre 08:00 $\mathrm{h}$ e 16:00 h. Durante as observações de visitas noturnas registou-se a presença de indivíduos de Ectatomma brunneum, presentes em ambos os turnos (Fig. 8 B).

Quanto ao comportamento de coleta, as formigas foram avistadas tanto em NEFs de pecíolos como nos de base floral, sendo observadas com mais frequência nos primeiros. Transitando entre as glândulas através dos ramos caulinares, de modo geral, as formigas abordavam os nectários com as pernas anteriores utilizadas na coleta do recurso, sendo apoiadas nas pernas posteriores, circundando assim o nectário durante a visita (Figs 9A-G).

Dentre os Formicidae, indivíduos E. brunneum frequentemerı exibiram comportamento de proteção em relação ao forrageio nas glândulas secretoras. Inclusive exibindo comportamento agonístico com outras espécies de insetos, principalmente de formigas afastando qualquer outro indivíduo que se aproximasse dos nectários onde realizava a coleta do néctar. Apoiando-se nas patas posteriores, estas formigas prostravamse eretas e faziam movimentos com as mandíbulas e patas anteriores a fim de repelir o outro indivíduo. Em média, as durações das visitas variavam entre 15 e 107 segundos entre as espécies visitantes (Tabela 1). Durante as visitas de muitos segundos, era possível observar a dilatação do abdômen para acomodar o néctar ingerido.

Os dípteros foram registrados majoritariamente nos NEFs em torno do pedúnculo floral (Figs 9H-J), efetuando a coletar do néctar dos nectários próximos. Comumente era observado a ocorrência de mais de um indivíduo do grupo coletando em um mesmo anel de nectários, com visitas durando entre 15 e 140 segundos. Os demais grupos de insetos 

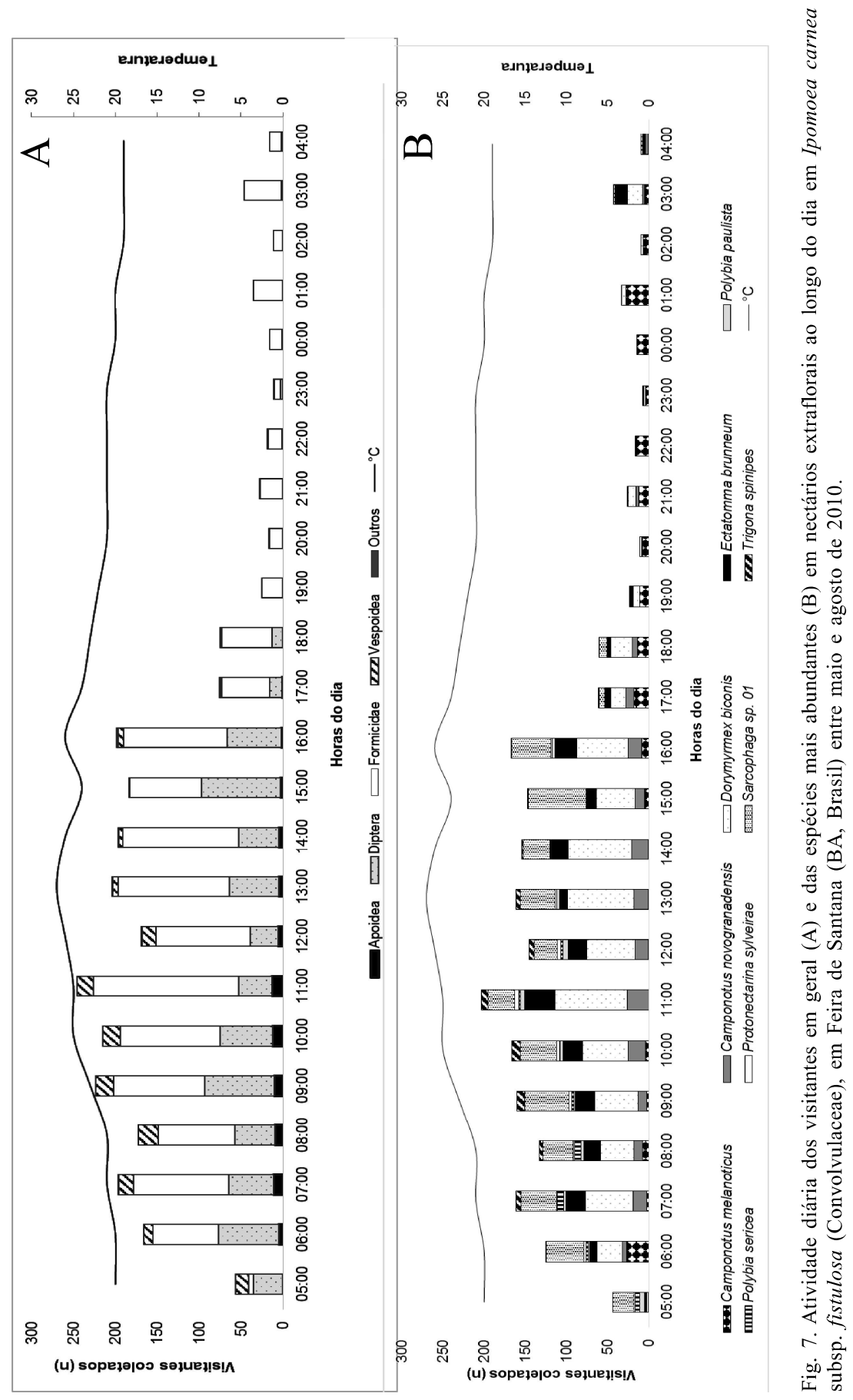


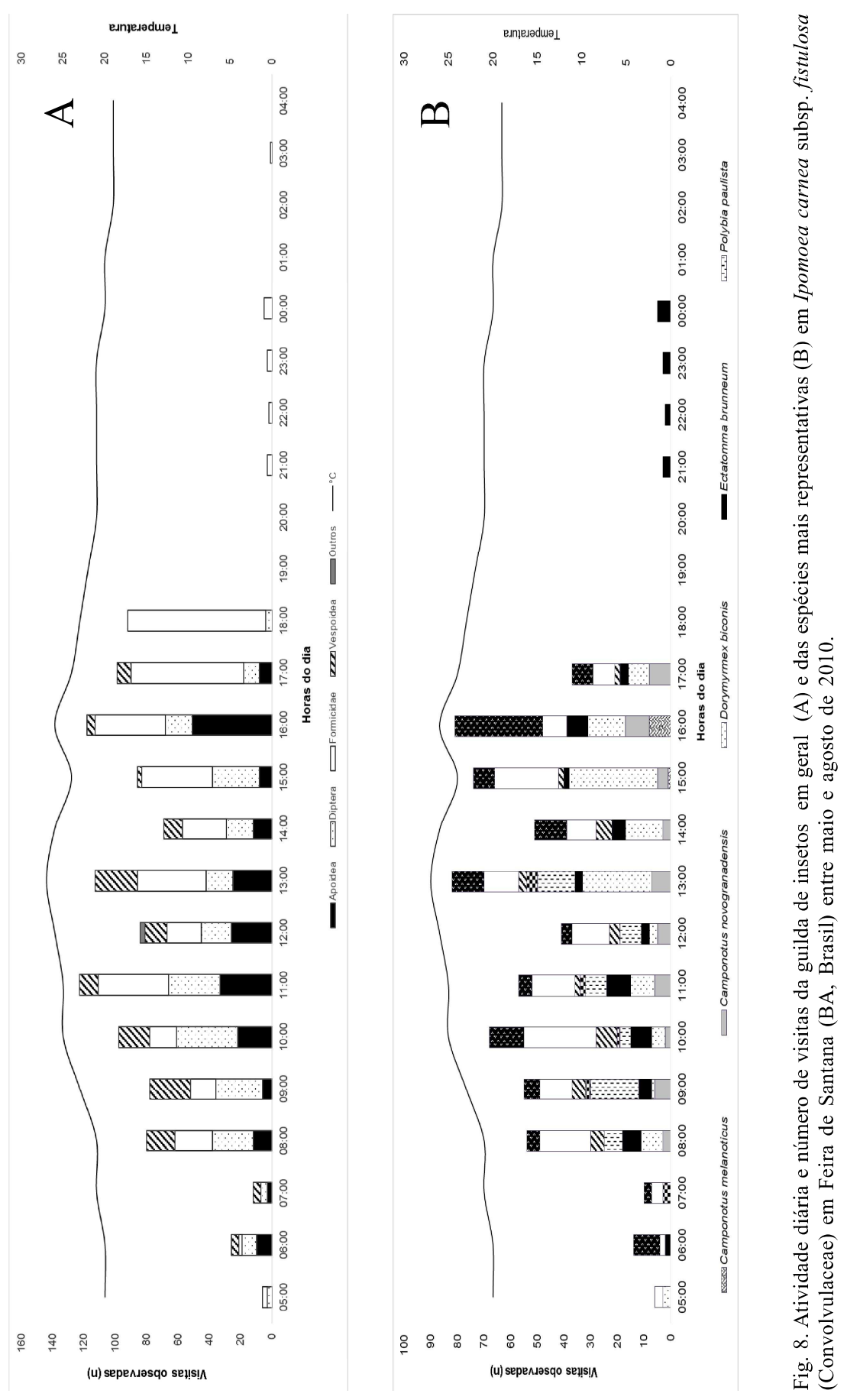



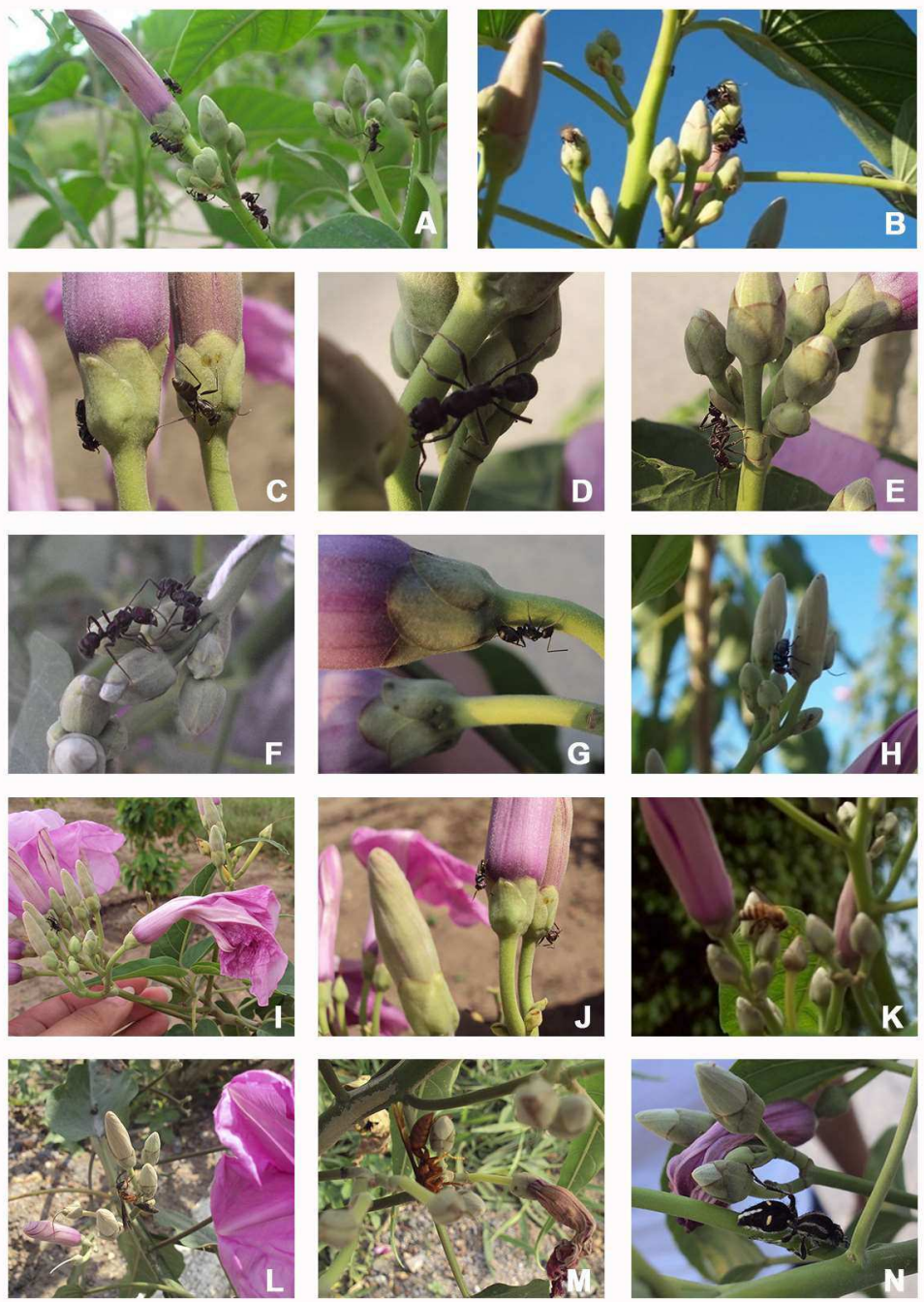

Fig. 9. Insetos visitantes de nectários extraflorais em Ipomoea carnea subsp. fistulosa (Convolvulaceae), no Semiárido da Bahia, Brasil, entre maio e agosto de 2010. Formigas forrageando de maneira solitária ou em pequenos grupos, na base de botões e flores: Ectatomma brunneum Smith, 1858 e Camponotus leydigi Forel, 1886 (A); Camponotus leydigi Forel, 1886 (B), Camponotus blandus (Smith, 1858) (C e G); Ectatomma brunneum Smith, 1858 (D) e (F) e Dolichoderus voraginosus Mackay, 1993 (E). Moscas forrageando em glândulas extraflorais, Calliphoridae spp. (I) e (J) e Sarcophaga sp. (H). Apis mellifera scutellata (Lepeletier, 1836)coletando néctar extrafloral. Vespas aculeata Polybia sericea (Olivier, 1791) (M); Polistes canadensis (Linnaeus, 1758) (N) e Traumatomutilla sp. cf. (Mutillidae) (O) forrageando em botões em estágio inicial. 
não exibiram comportamento muito diferenciado para a coleta da secreção açucarada, com forrageio em ambos os nectários.

As abelhas e vespas visitavam ambos os grupos de glândulas nectaríferas, onde, após o pouso inseriam o aparelho bucal, para a coleta do néctar. As visitas das abelhas variaram entre 3 e 48 segundos (Fig. 9L), ao passo que as visitas das vespas, em média duravam mais tempo, com intervalo entre 2,5 s e $107 \mathrm{~s}$ (Tabela 1) (Figs 9M-O). Frequentemente, indivíduos de Apis mellifera, inclusive, alternavam a coleta de néctar oriundo de nectário extrafloral e o nectário intrafloral, nesta última maneira, tornando um visitante floral legítimo.

No entanto, ocasionalmente, registrou-se em campo a ocorrência de comportamento agonístico entre Polybia paulista e Polybia sericea (Vespidae) e formigas do gênero E. brunneum (Ectatomminae), ou ainda com moscas Sarcophaga sp. (Sarcophagidae). As formigas apresentavam comportamento de defesa e proteção das glândulas nectaríferas também com abelhas, reportados para $T$. spinipes e $A$. mellifera.

\section{DISCUSSÃO}

Assim como em I. carnea subsp. fistulosa, os NEFs estão presentes em outros representantes do gênero Ipomea L. (KEELER, 1975; KeELER, 1977; KeELER, 1980; Mondal et al., 2013), o gênero mais representativo da família Convolvulaceae. A presença do néctar extrafloral, composto essencialmente de açúcares (PACCINI et al., 2003; NiCOLsON et al., 2007) atrai uma diversificada entomofauna aos vegetais. Sendo um componente importante na dieta da maioria destes animais (COLEY \& BARONE, 1996).

De acordo com ZimMERMANN (1932) os nectários extraflorais peciolares encontrados em Ipomoea carnea subsp. fistulosa, denominados criptas, são classificados como estruturalmente os mais complexos, pois exibem uma formação de câmaras com tricomas secretores ligados à superfície. Em virtude disso, alguns estudos com espécies co-genérica vêm sendo desenvolvidos no intuito de se entender os benefícios da interação entre NEFs e visitantes no crescimento e desenvolvimento de diversas plantas dentro da família Convolvulaceae (Keeler, 1975; KeEler, 1977; Keeler, 1978; Keeler \& KaUl, 1979; Keeler, 1980; Bhatia et al., 2007, Mondal et al., 2013; PAZ et al., no prelo).

Alguns autores sugerem que a posição dos nectários pode influenciar na quantidade secretora de néctar nas convolvuláceas. Na literatura, os registros mencionam que as glândulas localizadas nas folhas secretam menor volume de substância açucarada, quando comparadas às do anel peduncular, presente na base das flores e botões, como reportado para (Mondal et al., 2013). Ou ainda, os nectários pedunculares podem ser 
mais atrativos aos visitantes do que os pedicelares, como registrado em Ipomoea leptophylla Torr. (KeELer, 1980). Em ambos os estudos reportados, as estruturas de NEFs são semelhantes aos de I. carnea subsp. fistulosa.

Keeler (1975), Keeler (1977) e Keeler \& Kaul (1979) em seus trabalhos com Ipomoea carnea Jacq. detalharam a morfologia das glândulas nectaríferas, bem como, a composição química da substância secretada, além de padrões relacionados ao forrageio de visitantes. FRISCH (1971) apud KEELER (1977) sugere que a predominância de formigas nos nectários pedicelares das folhas estão relacionadas com a composição de aminoácidos presentes na secreção, especialmente o rafisone, este último altamente atrativo aos Formicidae. Ao passo que, a composição dos nectários pedunculares, presentes em flores e botões, apresenta uma composição de aminoácidos diferenciada, atrativa às abelhas e vespas, e principalmente aos dípteros.

Ambas as hipóteses discutidas: diferenças no volume secretado ou diferenças na composição química do néctar relacionada com as necessidades nutricionais dos visitantes de I. carnea subsp. fistulosa podem justificar a predominância dos demais grupos de insetos em glândulas extraflorais pedunculares. A preferência de formigas pelos nectários foliares fica clara neste estudo.

A presença de flores durante todos os meses observados neste estudo, e sem interrupções durante todo o ano, assim como relatado por PAZ et al. (2013) para a mesma área de estudo, também potencializa a maior oferta de recursos disponíveis, através dos NEFs pedunculares à guilda de insetos visitantes. Segundo PAZ et al. (2013) o incremento de flores com diferentes longividades e diferentes quantidades de recursos durante três momentos do dia, e que se sobrepõem em um mesmo indivíduo de planta, o que por consequência aumenta a atratividade à comunidade de visitantes florais.

Adicionalmente, essa atratividade no incremento de flores abrindo durante três momentos do dia pode estender-se e funcionar aos visitantes de NEFs, pois pode representar mais recursos disponíveis a entomofauna. Haja vista que, durante todo o intervalo de hora foram contabilizadas visitas às glândulas extraflorais ao longo de todos os meses estudados, assim como também é reportado para os visitantes florais legítimos nos estudos de PAz et al. (2013). Além disso, a correlação positiva encontrada neste estudo, entre o total de insetos coletados e a quantidade de flores disponíveis também reforça a ideia de benefício na atratividade da comunidade de visitantes. 
KeELER (1975) classificou como abundante a produção de néctar, com a produção quase contínua ao longo do dia. As observações no presente estudo também sugerem um comportamento semelhante, por tratar-se de uma subespécie, com uma secreção contínua de néctar, uma vez que foi visitada durante todos os intervalos de hora, o que torna a espécie de planta muito atrativa à guilda visitante. Podendo ser considerada uma importante fonte de recurso energético, sobretudo quando consideramos a ocorrência de I. carnea subsp. fistulosa em ambientes antropizados, como é a área em estudo.

KEELER (1978) também salienta que não há variação na composição, nem no volume de néctar extrafloral secretado ao longo do dia. Mas, apenas quando considerado o volume do néctar ao longo das estações do ano, sendo mais abundante na estação seca, e menos volumoso na estação chuvosa.

A distribuição de todos os grupos de insetos ao longo do período diurno, possibilita a concentração quase exclusiva de formigas durante o período noturno na coleta do néctar. Progressivamente, esta situação pode proporcionar o desenvolvimento de uma relação mais estreita entre as formigas e a planta em questão, uma vez que estas estão presentes durante $24 \mathrm{~h}$, que a longo prazo pode beneficiar o vegetal. Ao mesmo tempo que, consequentemente torna as visitas e utilização das glândulas nectaríferas no período diurno mais disputadas entre a guilda visitante

As formigas foram os insetos predominantes em abundância em $I$. carnea subsp. fistulosa (61,0\%), assim como na maioria dos estudos com visitantes de NEFs descritos na literatura (J ANZEN, 1966; BentLeY, 1977; Bronstein, 1998; Oliveira \& Pie, 1998; Oliveira \& Freitas, 2004; Koptur et al., 2010; SCHOEREDER et al., 2010), podendo corresponder até $80 \%$ de todos os visitantes (KeELER, 1975). Nas investigações de KeELER (1978) na Costa Rica, com I. carnea relata-se o encontro de valores semelhantes, em relação à presença das formigas no decorrer da observação, as quais estavam presentes em 53,3 \% do tempo. No entanto, a predominância de formigas, provavelmente está associado ao papel ecológico desses insetos nos nectários, a partir do comportamento de proteção dessas plantas contra danos e herbivoria ao vegetal (KEELER, 1977).

Além de formigas, outros insetos visitantes com menos destaque na literatura são comuns às glândulas nectaríferas externas em espécies de Convolvulaceae, tais como: vespas, abelhas, moscas e besouros (KeELER, 1975; Keeler, 1977; Beckmann Jr. \& Stucky, 1981; Marques et al., 2005; PAZ, 2011), e mais raramente, outros artrópodos, como aranhas e ácaros (Pollard et al., 1995; Taylor \& Pfannenstiel, 2008). Ademais, 
outros trabalhos com a mesma espécie (I. carnea), ou com representantes do gênero, também registraram diversidade de gêneros e famílias semelhantes $(44,4 \%)$, quando comparado com os insetos visitantes do presente estudo. Na Tabela 2, pode-se observar que a maioria dos grupos visitantes são comuns às outras plantas convolvuláceas na região tropical.

Formigas dos gêneros Camponotus, Pseudomyrmex (muitas espécies), e Ectatomma, Dolichoderus (poucas espécies) são visitantes frequentes de glândulas nectaríferas em convolvuláceas, haja vista que, na maioria dos trabalhos, tais gêneros de Formicidae são mencionados (KeELER, 1975; Mondal et al., 2013). A frequência, abundância e riqueza de espécies destes insetos foi observada durante todo o período de estudo, em ambos os turnos, o que pode sugerir que esta seja uma importante fonte de recurso alimentar para estas formigas presentes em ambientes antropizados do semiárido.

Por possuírem colônias com proles numerosas, as formigas demandam de uma grande quantidade de alimentos, sendo essencial uma intensa e constante atividade de forrageio para sua manutenção. Assim, as formigas tornam-se mais ativas na procura de alimentos, do que outros visitantes, pois dela dependem o desenvolvimento de toda a colônia. Essa incessante busca por alimento pôde ser observada ao longo de toda a atividade de secreção dos NEFs, que nesta espécie vegetal ocorre durante todo o dia, onde formigas apresentaram-se muito abundantes inclusive à noite.

Em observação de NEFs em Chamaecrista debiilliis (Vogel) Irwin Barneby (Caesalpiniaceae), Nascimento \& Del-Claro (2007) sugerem que as formigas têm como meta principal a proteção de um recurso alimentar previsível no tempo e no espaço, como o néctar extrafloral. E, por consequência, acabam protegendo indiretamente a planta, quando forrageiam nesse substrato ambiental na busca por proteína. De maneira complementar, a possibilidade de ocorrência de algumas espécies de Formicidae nidificarem próximos às plantas utilizadas na dieta alimentar, pode facilitar a movimentação destes animais pela rota de forrageio independentemente do horário.

Quanto aos dípteros, animais que apresentam uma dieta bastante diversificada, por isso são polífagos, a atração destes aos NEFs pode ser justificada pela acessibilidade do aparelho bucal destes animais, sendo geralmente do tipo lambedor ou sugador (GILlOT, 2005), ao recurso energético, o néctar, relativamente disponível. Relativamente porque a disposição deste néctar não requer um aparato bucal estritamente especializado para coleta, nem um comportamento de coleta muito elaborado para nenhum grupo visitante. No estudo de KeELER (1977), as moscas foram encontradas em $29,9 \%$ do tempo de observação nos 
Tabela 2. Insetos visitantes de nectários extraflorais (NEFs) registrados em estudos com espécies de Convolvulaceae em regiões tropicais.

\begin{tabular}{|c|c|c|c|}
\hline Familia & Espécie & Planta risitada & Trabalho de referênnia \\
\hline \multicolumn{4}{|l|}{ COLEOPTERA } \\
\hline Coccinellida & & Ipomerea camerea Jaç. & 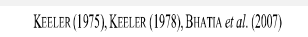 \\
\hline \multirow[t]{2}{*}{ Chrysomelidae } & & Ipomonea camea Jace. & 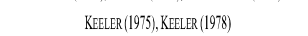 \\
\hline & Diabroticaspp. & Ipomerea cameal Jacq. & 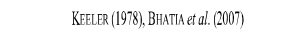 \\
\hline DIPTERA & & Ipomeon cameal Jacq. & $\operatorname{KeELLR}(1975)$ \\
\hline Dresspililidae & & Ipomerea camear Jace. & KeELER (1978) \\
\hline Sarcophagidae & & Ipomber canera Jace. & Keftert (1978) \\
\hline \multicolumn{4}{|l|}{ Tabanidae } \\
\hline & Tabamus sp. & Ipomerea camear Jace. & KefterR (1988) \\
\hline Clidididae & Envertasp. & Iponmeer cameal Jacy. & $\operatorname{KeELER}(1978)$ \\
\hline \multicolumn{4}{|l|}{ HYMENOPTERA } \\
\hline \multicolumn{4}{|l|}{ Apidae } \\
\hline & 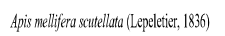 & Ipommea camear Jace. & KeELER (1978) \\
\hline & Trigonu sp. & Ipommea camear Jace. & KeEterR (1978) \\
\hline Chalcididiae & Chalididatas sp. & Ipomear cameal Jacq. & Kefeter (1978) \\
\hline \multicolumn{4}{|l|}{ Formicidae } \\
\hline \multicolumn{4}{|l|}{ Dolichoderinae } \\
\hline & Dolichoderns sp. & 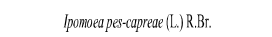 & MoNDLLetal. (2013) \\
\hline & Dorymymex sp. & Ipomweal eptophlylla Tor. & Kefletr (1980) \\
\hline \multicolumn{4}{|l|}{ Ectatomminae } \\
\hline & Ectatommasp. & 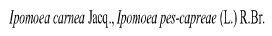 & KeEEER (1975),KEELER(1978) \\
\hline \multicolumn{4}{|l|}{ Formininae } \\
\hline & Camponotus spp. & 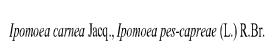 & 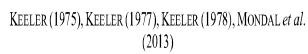 \\
\hline \multicolumn{4}{|r|}{$\sin ^{2}(\mathrm{sin})$} \\
\hline & Psendonymmer spp. & 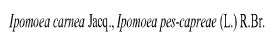 & 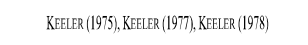 \\
\hline \multirow[t]{4}{*}{ Vespidae } & & Ipomoea camiea Jaç. & $\operatorname{KeELER}(1975)$ \\
\hline & Brachygastra sp. & Ipomonea camea Jace. & $\operatorname{KeELLR}(1978)$ \\
\hline & Polistes canadensis (Limnaus, 1758) & Ipomeer camear Jaca. & KeELER (1978) \\
\hline & Polbbia occidentalis (Oliver, 1791) & Ipomoea camiea Jacy. & KEELER (1977), KEELER (1978) \\
\hline
\end{tabular}

NEFs de $I$. carnea, valores também semelhantes ao do estudo atual $(28,1 \%)$.

Representantes das famílias de moscas Sarcophagidae, Ulidiidae e Calliphoridae são indivíduos presentes como coletores de exsudatos açucarados vegetais, utilizando como recurso energético, e listados em trabalhos com esta abordagem, em espécies de diversas famílias botânicas (Boff et al., 2008; Monteiro, 2008; Vilhena-Potiguara et al., 2012). As moscas são essencialmente predominantes no período diurno, ou nos momentos com temperaturas mais quentes ao longo do dia, assim como observado neste estudo em Feira de Santana (BA). 
As abelhas e vespas coletadas inventariadas neste estudo são na sua grande maioria espécies sociais, que demandam de alimentos para proles numerosas. Assim, a ocorrência de NEFs com relativa facilidade de acesso ao aparelho bucal destes grupos, também pode representar uma interessante fonte de recursos no ambiente, ao menos de maneira sazonal. Uma vez que as densidades de outras fontes de recursos florais podem influenciar no comportamento de forrageio desses insetos.

Vespas sociais (Vespidae) são visitantes tipicamente generalistas (Hermes \& KöHLER, 2006) de nectários acessíveis ao seu aparelho bucal, como os de I. carnea subsp. fistulosa. O mesmo comportamento referese às abelhas sociais, em especial A. mellifera e T. spinipes (Apidae), espécies reconhecidamente como generalistas, por exibirem forrageio em um amplo espectro de famílias botânicas. Concentrando as suas atividades em plantas que oferecem recursos florais abundantes, ou ainda de fácil acessibilidade aos mesmos. Por isso, representantes destes grupos são com frequência relatados como visitantes de nectários extraflorais em Convolvulaceae (Keeler, 1975, Keeler, 1978, Mondal et al., 2013; PAz et al., no prelo) e de famílias de plantas (JANZEN \& SCHOENER, 1968; Marques et al., 2005; Paiva \& Machado, 2006; Krieck, 2008).

O mutualismo entre formigas e plantas é considerado por muitos autores como uma relação das mais especializadas, em que geralmente a formiga confere à planta proteção contra a herbivoria em troca de alimento (KeEler, 1977; Ferreira, 1994; Oliveira, 1997; Oliveira et al., 1999; Heil et al., 2001; Santos \& Del-Claro, 2001; Madureira \& Sobrinho; 2002; Bertuol et al., 2008; Knoechelmann \& Morais, 2008; RosUMEK, 2008).

Nos resultados do estudo de KeELER (1977), o autor sugere que as observações apoiam uma interpretação de formigas-guardas em nectários extraflorais de Ipomoea carnea, a partir de análises do rol de dados de herbivoria em ramos com maior ou menor abundância de formigas, verificando que, onde as formigas estavam mais presentes o percentual de danos foi reduzido, confirmando a teoria de mutualismo de defesa. Mondal et al. (2013) também descreve um comportamento de patrulhamento e defesa do recurso por parte de várias espécies de formigas em Ipomoea pes-capreae (L.) R.Br.

Ainda em referência às formigas, as espécies: Ectatomma brunneum, Camponotus novogranadensis Mayr, 1870, Camponotus melanoticus Emery, 1894, Camponotus blandus (Smith, 1858) e Camponotus atriceps (Smith, 1858), apresentaram-se atuantes no patrulhamento das glândulas de néctar. Essas formigas (E. brunneum, C. melanoticus e C. blandus), além das vistorias em NEFs, também exibiram 
agressividade perante a abordagem da planta por um outro visitante, seja formiga ou outro inseto, caracterizando o comportamento do mutualismo de defesa tipificado por muitos autores (JANZEN, 1966; SiLVESTRE et al., 2003; Del-Claro, 2004). Reforçando essa ideia de proteção para o modelo observado em I. carnea subsp. fistulosa, a partir da exclusão e do comportamento agonístico dos outros visitantes. E de que quanto mais próximas as formigas ficam próximas aos NEFs, maior é a proteção (Oliveira, 1997).

Espécies de formigas da subamília Dolichoderinae geralmente são onívoras e forrageiam na superfície do solo, alimentando-se também de exsudatos vegetais açucarados (Lopes et al., 2010), como os NEFs da planta analisada. O gênero Pseudomyrmex reúne formigas que também forrageiam em NEFs, extremamente ágeis no seu forrageio, quase exclusivamente de hábito diurno, e que segundo SILVESTRE et al. (2003) costumam antecipar a sua visita aos recursos tróficos, evitando assim a sobreposição.

Dorymyrmex é um gênero exclusivamente americano, e é um dos mais importantes ecologicamente (Cuezzo, 2003), pois seus representantes costumam construir ninhos em solos de regiões áridas ou semiáridas com pouca cobertura vegetal, como a área do presente estudo. Ectatomma é endêmico da América do Sul, que também contempla espécies de hábito generalista e oportunista, que podem nidificar em ambientes urbanos e antropizados (Brown, 1958), podendo ser considerada uma espécie sinantrópica. Podem forragear solitariamente, mas podem realizá-lo em pares ou em grupos de indivíduos, e exibir comportamento agonístico para a proteção do recuso trófico.

Outro gênero de Formicidae que exibiu alta diversidade de espécies neste estudo, Componotus é considerado hiperdiverso, cosmopolita, e nidifica em diversos ambientes e microhabitats, com algumas espécies sinantrópicas (OliveIRA \& CAMPOS-FARINHA, 2005). Segundo ZoRZENON et al. (2011), a maioria das espécies, que podem apresentar forrageio individual ou em grupos com número de indivíduos variados, geralmente exibem hábito de forrageio noturno, como relatado no período de estudo. Várias espécies do gênero são consideradas espécies dominantes de formigas patrulheiras, podendo ser inclusive agressivas assim, coletam alimentos de maneira massiva, muito comuns em ambientes antropizados, como o ambiente em questão.

As espécies mais importantes no forrageio de exsudatos energéticos de I. carnea subsp. fistulosa foram aquelas que exibiram: maior número de indivíduos coletados, maior número de visitas realizadas, e foram mais constantes ao longo dos meses. No entanto, a diferença entre a 
interpretação desses dois tipos de dados (Figs 6 e 7) podem estar associadas à fidelidade aos recursos florais, e a amplitude da dieta dos grupos em questão. A exemplo das vespas aculeta e abelhas, que apresentam uma estreita relação com o néctar, como uma fonte energética indispensável aos indivíduos adultos (RouBIK, 1989, HuNT, 2007), e foram mais representativos em quantidade de visitas do que em número de indivíduos coletados. Ao mesmo tempo que, os dípteros e formigas, que potencialmente apresentam um amplo espectro de recursos tróficos, mantiveram relativamente as mesmas proporções em abundância e número de visitas.

As glândulas extraflorais aparentemente parecem não participar diretamente na biologia reprodutiva da espécie em questão, apesar de alguns visitantes de NEFs também serem visitantes legítimos das flores (a exemplo de todas as abelhas listadas no presente estudo), e com relativa participação na polinização de I. carnea subsp. fistulosa. No entanto, de maneira indireta, o patrulhamento de formigas nos NEFs pode contribuir para o melhor desenvolvimento das plantas, e consequentemente potencializar o fitness reprodutivo.

\section{CONSIDERAÇÕES FINAIS}

Ipomoea carnea subsp. fistulosa é uma espécie nativa ruderal, perene e ocorrente em ambientes abertos. Caracterizada pela relativa facilidade ao acesso aos seus numerosos nectários extraflorais, frequentados abundantemente por formigas, e que provavelmente apresentam uma função defensiva, além de serem visitados por outros grupos de insetos. Essas características, associadas ao fato de presença de flores e a secreção de nectários extraflorais, ambos continuamente ao longo do dia e dos meses, e da grande diversidade atraída por estes NEFs, sem dúvida, torna a planta em questão uma importante fonte de recurso trófico a comunidade entomofaunística no semiárido, sobretudo quando consideramos ambientes antropizados e urbanos, onde os recursos podem ser ocasionais ou escassos.

\section{SUMÁRIO}

Guilda visitante de nectários extraflorais em Ipomoea carnea subsp. fistulosa (Mart. ex Choisy) D.F. Austin (Convolvulaceae) em uma área de semiárido antropizado da Bahia, Brasil - Representantes do gênero Ipomoea costumam ser espécies ruderais, presentes em ambientes antropizados, com numerosos nectários extraflorais (NEFs) na base das folhas e flores/botões, muito atrativos aos visitantes. Assim, este trabalho objetivou inventariar a guilda visitante de nectários extraflorais em Ipomoea carnea subsp. fistulosa. Para tal, 17 indivíduos botânicos foram 
marcados, e acompanhados mensalmente, entre maio e agosto de 2010, em uma área antropizada do Semiárido (BA). As coletas e observações foram realizadas entre 05:00 h às 18:00 h, com visitas complementares noturnas (18:00 h às 05:00 $\mathrm{h}$ ), executadas por dois coletores com redes entomológicas. Os NEFs secretam néctar ininterruptamente durante 24 $\mathrm{h}$, exibindo visitas durante todos os meses e intervalos de hora. No total, 2.602 insetos foram coletados, dentre formigas, abelhas, vespas, dípteros, besouros e borboleta, pertencentes a 45 espécies. Dorymyrmex biconis, Sarcophaga sp., Ectatomma brunneum e Camponotus melanoticus foram as espécies mais frequentes. Os visitantes diurnos foram mais representativos, em comparação aos noturnos, sendo as formigas as mais abundantes em ambos os turnos, exibindo comportamento de defesa do recurso. A planta estudada representa uma fonte alimento à entomofauna local, especialmente quando consideramos ambientes antropizados no Semiárido, onde os recursos podem ser ocasionais ou escassos.

PalaVras-chave: Insetos; Apoidae; Diptera; Formicidae; Vespoidae

\section{SUMMARY}

Extrafloral nectaries visitors guild of Ipomoea carnea subsp. fistulosa (Mart. ex Choisy) D. F. Austin (Convolvulaceae) in an area of antropized semiarid Bahia, Brazil - Ipomoea representatives often ruderal species, present in anthropogenic environments with numerous extrafloral nectaries (EFNs) in the base of the leaves and flowers/floral button very attractive to visitors. This study aimed to survey the visitor guild extrafloral in Ipomoea carnea subsp. fistulosa. To this end, 17 botanical individuals were marked and monitored monthly between May and August 2010, in a disturbed area Semiarid (BA). The collections and observations were conducted between $05: 00 \mathrm{~h}$ to $18: 00 \mathrm{~h}$, with additional nocturnal visits (18:00 h to $05: 00 \mathrm{~h}$ ), executed by two collectors with entomological nets. The EFNs secrete nectar continuously for 24 hours, exhibiting visits during each month and time intervals. In total, 2.602 insects were collected, among ants, bees, wasps, flies, beetles and butterfly, pertaining to 45 species. Dorymyrmex biconis, Sarcophaga sp., Ectatomma brunneum and Camponotus melanoticus were the most frequent species. The diurnal visitors were more representative, compared to nocturnal, being the most abundant ants in both rounds, exhibiting resource protection behavior. The plant studied represents a food source for the local insect fauna, especially when considering anthropogenic environments in semiarid where resources may be limited or occasional.

KEY wORDS: Insects; Apoidae; Diptera; Formicidae; Vespoidae 


\section{RESUMÉ}

Guild des visiteurs des nectaires extrafloral en Ipomoea carnea subsp. fistulosa (Mart. ex Choisy) D. F. Austin (Convolvulaceae) dans une zone semi-aride anthropique de Bahia, Brésil - Représentants Ipomoea souvent des espèces rudérales présents dans des environnements anthropiques avec de nombreux nectaires extrafloraux (EFNs) dans la base des feuilles et des fleurs/boutons de fleurs, très attractifs pour les visiteurs. Cette étude visait à enquête le visiteur dans guild extrafloral Ipomoea carnea subsp. fistulosa. À cette fin, 17 individus botaniques ont été marqués et suivis mensuellement entre Mai et Août 2010, dans une zone perturbée Semi-aride (BA). Les collections et les observations ont été réalisées entre 5:00 h-18:00 h, avec des visites supplémentaires de nuit (18:00 $\mathrm{h}-5: 00 \mathrm{~h}$ ), effectuées par deux collectionneurs avec des filets entomologiques. Les EFNs sécrètent du nectar en continu pendant $24 \mathrm{~h}$, montrant visites pendant chaque mois d'intervalle et de temps. Au total, 2.602 insectes ont été collectés, comment les fourmis, les abeilles, les guêpes, les mouches, les coléoptères et papillon, appartenant à 45 espèces. Dorymyrmex biconis, Sarcophaga sp., Ectatomma brunneum et Camponotus melanoticus étaient les espèces les plus fréquentes. Visiteurs diurnes étaient plus représentatifs, comparativement aux visiteurs nocturnes, étant les fourmis les plus abondants dans les deux tours, affichant un comportement de protection des ressources. La plante étudiée représente une source d'alimentation pour la faune locales d'insectes, en particulier lorsque l'on considère les environnements anthropiques en Semi-aride où les ressources peuvent être rares ou occasionnelle.

MoTs-CLÉs: Insectes; Apoidae; Diptera; Formicidae; Vespoidae

Agradecimentos - Os autores agradecem à Fundação de Amparo à Pesquisa do Estado da Bahia (FAPESB) pela bolsa de mestrado concedida à primeira autora. À Dra. Rosângela Simão-Bianchini (IBot-SP) pela identificação da espécie botânica. Aos especialistas: Dra. Favízia F. de Oliveira (UFBA-BA), MSc Thiago Mahlmann V. L. Muniz (UFBA-BA), Dr. Sérgio R. Andena (UEFS-BA) e Dr. Jacques H. C. Delabie (UESC/CEPLAC-BA) pela identificação dos himenópteros. Ao Dr. Carlos José E. Lamas (MZUSP-SP), MSc. Ivan Farias Castro (UEFS-BA) e Dra. Miriam N. Morales (UFMG-MG) pela identificação dos dípteros. À MSc. Thamara Zacca B. Taumaturgo (UFPR-PR) pela identificação dos lepidópteros. À Dra. Priscila P. Lopes (UEFS-BA) pela identificação dos coleópteros. À Unijorge pela disponibilização de materiais e instrumento para o desenvolvimento das atividades. A todos os colegas que colaboraram para o desenvolvimento do trabalho em campo e no laboratório. 


\section{BIBLIOGRAFIA}

Beckmann JR., R. L. \& J. M. Stucky. 1981. Extrafloral nectaries and plant guarding in Ipomoea pandurata (L.) G. F. W. Mey (Convolvulaceae). American Journal of Botany 68 (1):72-79.

BENTLEY, B. L. 1977. Extrafloral nectaries and protection by pugnacious bodyguards. Annual Review of Ecology, Evolution, and Systematics 8: 407-428.

Bertuol, T. J.; C. Galbiati; M. J. B. Pereira \& A. M. Amaral. 2008. Avaliação de mutualismo entre Acacia mangium Willd (Mimosaceae) e formigas. Revista Brasileira de Agroecologia 3: 41-47.

Bhatia, S.; I. Mенmood \& M. Singh. 2007. Insects associated with Ipomea carnea Jacq. (Convolvulaceae) in Jammu and their potential for its biological control. Journal of Crop and Weed 3 (2): 56-58.

Blüthgen, N.; M. VerhaAgh; W. Goitia; K. JafFé; W. MoraWetz \& W. BARthlott. 2000. How plants shape the ant community in the Amazonia rainforest canopy: the key role of extrafloral nectaries and homopteran honeydew. Oecologia 125: 229-240.

BLÜTHGER, N. \& K. REIFENRATH. 2003. Extrafloral nectaries in an Australian rainforest - structure and distribution. Australian Journal of Botany 51:515-527.

Boff, S.; G. Graciolli; A. G. Boaretto \& M. R. Marques. 2008. Insetos visitantes de gomas exsudadas por Terminalia argentea Mart \& Zucc (Combretaceae). Revista Brasileira de Entomologia 52 (3): 477-479.

BRONSTEIN, J. L. 1998. The contribution of antplant protection studies to our understanding of mutualism. Biotropica 30 (2): 150-161.

Brown, W. L. JR. 1958. Contributions toward a reclassification of the Formicidae. II. Tribe Ectatommini (Hymenoptera). Bulletin of the Museum of Comparative Zoology 118 (5): 175-362.

Charão, L. S. 2005. Polinização em Acacia mearnsii De Wild. Revista de Ciencias Agro-Ambientais 3: 92-109.

Cogni, R.; A. V. L. Freitas \& P. S. Oliveira. 2003. Interhabitat differences in ant activity on plant foliage: ants at extrafloral nectaries of Hibiscus pernambucensis in sandy and mangrove forests. Entomologia Experimentalis et Applicata 107: 125-131.

Coley, P. D. \& J. A. Barone. 1996. Herbivory and plant defenses. Annual Review of Ecology and Systematics 27: 305-335.

CuEzzo, F. 2003. Subfamília Dolichoderinae. In: Fernández, F. (Ed.). Introducción a las hormigas de la región Neotropical. Bogotá-COL. Instituto de Investigación de Recursos Biológicos Alexander Von Humboldt, 2003. p. 291-298. 
Dáttilo, W.; E. C. Marques; J. C. F. Falcão \& D. D. O. Moreira. 2009. Interações mutualísticas entre formigas e plantas. EntomoBrasilis 2 (2): 32-36.

Del-Claro, K. 2004. Multitrophic relationships, conditional mutualisms, and the study of interaction biodiversity in tropical savannas. Neotropical Entomology 33 (6): 665-672.

Diniz, A. F.; R. L. Santos \& S. M. SAnto. 2008. Avaliação dos riscos de seca para o município de Feira de Santana-BA associado à influência do El niño no semi-árido do Nordeste brasileiro. Geografia's 1: 18-24.

FERreira, S. O. 1994. Nectários extraflorais de Ouratea spectabilis (Ochnaceae) e a comunidade de formigas associadas: um estudo na vegetação em Cerrado, no Sudeste do Brasil. Dissertação de Mestrado. Universidade Estadual de Campinas, Campinas, SP, Brasil. $75 \mathrm{pp}$.

Fiala, B. \& U. Maschwitz. 1991. Extrafloral nectaries in thegenus Macaranga (Euphorbiaceae) in Malaysia: comparative estudies of their possible significance as predispositions for myrmecophytism. Biological Journal of the Linnean Society 44: 287-305.

Fidalgo, A. O. 1997. Ecologia floral de duas espécies invasoras de Ipomoea (Convolvulaceae). Dissertação de Mestrado. Universidade Estadual de Campinas. Campinas, SP, Brasil. 99 pp.

Gillot, C. 2005. Entomology. $3^{\text {a }}$ edição. University of Saskatchewan, Springer, Saskatoon, Saskatchewan, Canada. $831 \mathrm{pp}$.

Gotardo, A. T. 2009. Avaliação da toxicidade da Ipomoea carnea em caprinos durante o período perinatal: estudos de neuroteratologia. Dissertação de Mestrado. Universidade de São Paulo. Pirassununga, SP, Brasil. 122 pp.

Heil, M.; T. Koch; A. Hilpert; B. Fiala.; W. Boland \& K. E. Linsenmair. 2001. Extrafloral nectar production of the ant-associated plant, Macaranga tanarius, is an induced, indirect, defensive response elicited by jasmonic acid. Proceedings of the National Academy of Sciences 98 (3): 1083-1088.

Hermes, M. G. \& A. KöHLER. 2006. The flower-visiting social wasps (Hymenoptera, Vespidae,Polistinae) in two areas of Rio Grande do Sul State, southern Brazil. Revista Brasileira de Entomologia 50 (2): 268-274.

Hunt, J. H. 2007. The evolution of social wasps. Oxford University Press, New York, 259 pp.

JANZEN, D. H. \& T. W. SCHOENER. 1968; Differences in insect abundance and diversity between wetter and drier sites during a tropical dry season. Ecology 49: 69-110.

JANZEN, D. H. 1966. Coevolution of mutualism between ants and Acacias in Central America. Evolution 20 (3): 249-275. 
KeELER, K. H. \& R. B. KaUL. 1979. Morphology and distribution of petiolar nectaries in Ipomoea (Convolulaceae). American Journal of Botany 66 (8): 946-952.

KeEler, K. H. \& R. B. KaUl. 1984. Distribution of defense nectaries in Ipomoea (Convolvulaceae). American Journal of Botany 71(10): 1364-1372.

KeELeR, K. H. 1975. Ipomoea carnea Jacq. (Convolvulaceae) em Costa Rica. Brenesia 5: 1-6.

KeELer, K. H. 1977. The extrafloral nectaries of Ipomoea carnea (Convolvulaceae). American Journal of Botany 64(10): 1182-1188.

KeELER, K. H. 1978. Insects feeding at extrafloral nectaries of Ipomoea carnea. Entomological News 89: 163-168.

KeELER, K. H. 1980. The extrafloral nectaries of Ipomoea leptophylla (Convolvulaceae). American Journal of Botany 67: 216-222.

Knoechelmann, C. M ; H. C. Morais. 2008. Visita de formigas (Hymenoptera: Formicidae) a nectários extra florais de Stryphnodendron adstringens (Mart.) Cov. (Fabaceae, Mimosoideae) em uma área de cerrado frequentemente queimado. Revista Brasileira de Zoociências 10: 35-40.

Koptur, S.; A. William \& Z. Olive. 2010. Ants and plants with extrafloral nectaries in fire successional habitats on Andros (Bahamas). Florida Entomologist 93 (1): 89-99.

Koptur, S. 1992. Extrafloral nectary-mediated interactions between insects and plants, p.81-129. In: Bernays, E. (ed.) Insect-plant interactions v. 4. Boca Raton, CRC Press, 423 pp.

KriecK, C. 2008. Ecologia Reprodutiva de Dyckia encholirioides var. encholirioides (Gaud) Mez. (Bromeliaceae) em Costões Oceânicos em Florianópolis, Santa Catarina. Dissertação de Mestrado. Universidade Federal de Santa Catarina. Florianópolis, SC, Brasil. 67 pp.

Leal, I. R.; M. Tabarelli. \& J. M. C. Silva. 2003. Ecologia e conservação da Caatinga. Editora Universitária, Universidade Federal de Pernambuco, Recife, Brasil. 822 pp.

Lopes, D. T.; J. Lopes; I. C. Nascimento \& J. H. Delabie. 2010. Diversidade de formigas epigéicas (Hymenoptera, Formicidae) em três ambientes no Parque Estadual dos Godoy, Londrina, Paraná. Iheringia (Série Zoologia) 100: 84-90.

MACHADO, I. C. S. \&A. V. LOPES. 2004. Floral traits and pollination systems in the Caatinga, a Brazilian tropical dry forest. Annals of Botany 94: 365-376.

Madureira, M. \& T. G. Sobrinho. 2002. Evidência de mutualismo entre Qualea cordata e Cephalotes sp. Academia Insecta 2 (1): 1-4. 
MagurRan, A. E. 2003. Measuring Biological Diversity. Blackwell, Oxford, UK. 215 pp.

Marques, O. M.; P. A. Santos; A. F. Vinhas; A. L. V. Souza; C. A. L. Carvalho \& J. L. Meira. 2005. Vespas sociais (Hymenoptera: Vespidae) visitantes de nectários de Vigna unguiculata (L.) Walp. na região do Recôncavo da Bahia. Magistra 17 (2): 64-68.

Mondal, A. K.; T. Chakraborty \& P. S. Mondal. 2013. Ant foraging on extrafloral nectaries [EFNs] of Ipomoea pes-caprae (Convolvulaceae) in the dune vegetation: ants as potential antiherbivore agents. Indian Journal of Marine Sciences 42 (1): 67-74.

Monteiro, A. F. M. Diversidade de formigas (Hymenoptera: Formicidae) em sistemas de cultivo de algodoeiro no Distrito Federal. Dissertação de Mestrado. Universidade de Brasília. Brasília, DF, Brasil. 86 pp.

Nascimento, E. A. \& K. Del-Claro. 2007. Floral visitors of Chamaecrista debilis (Vogel) Irwin \& Barneby (Fabaceae Caesalpinioideae) at Cerrado of Estação Ecológica de Jataí, São Paulo State, Brazil. Neotropical Entomology 36 (4): 619-624.

Nicolson, S. W.; NePi, M. \& PAcini, E. (Eds.). 2007. Nectaries and nectar. Springer-Verlag, The Netherlands. $396 \mathrm{pp}$.

Oliveira, M. F. \& CAmpos-Farinha, A. E. C. 2005. Formigas urbanas do município de Maringá, PR, e suas implicações. Arquivos do Instituto Biológico 72 (1): 33-39.

Oliveira, P. S. \& Freitas, A. V. L. 2004. Ant-plant-herbivore interactions in the neotropical cerrado savanna. Naturwissenschaften 91: 557570. DOI: $10.1007 / \mathrm{s} 00114-004-0585-\mathrm{x}$

OliveirA, P. S. \& Pie, M. R. 1998. Interaction between ants and plants bearing extrafloral nectaries in cerrado vegetation. Anais da Sociedade Entomológica do Brasil 27: 161-176.

Oliveira, P. S.; Rico-Gray, V.; Díaz-Castelazo, C. \& Castillo-Guevara, C. 1999. Interaction between ants, extrafloral nectaries and insect herbivores in Neotropical coastal sand dunes: herbivore deterrence by visiting ants increases fruit set in Opuntia stricta (Cactaceae). Functional Ecology 13: 623-631.

Oliveira, P. S. 1997. The ecological function of extrafloral nectaries: herbivore deterrence by visiting ants and reproductive output in Caryocar brasiliense (Caryocaraceae). Functional Ecology 11: 323-330.

Pacini, E.; Nepi, M. \& Vesprini, J. L. 2003 Nectar biodiversity: a short review. Plant Systematics and Evolution 238:7-22.

Paiva, E. A. S. \& Machado, S. R. 2006. Ontogênese, anatomia e ultraestrutura dos nectários extraflorais de Hymenaea stigonocarpa Mart. 
ex Hayne (Fabaceae - Caesalpinioideae). Acta Botanica Brasilica 20 (2): 471-482.

Paz, J. R. L. DA; Gimenes, M. \& Pigozzo, C. M. 2013. Three diurnal patterns of anthesis in Ipomoea carnea subsp. fistulosa (Convolvulaceae): implications for temporal, behavioral and morphological characteristics of pollinators? Flora 208: 138-146.

PAz, J. R. L. da. 2011. Biologia Floral e Polinização Diurna e Noturna de Ipomoea carnea subsp. fistulosa (Mart. ex Choisy) D.F. Austin (Convolvulaceae) em uma Área Antropizada no Semi-árido da Bahia, Brasil. Dissertação de Mestrado. Universidade Estadual de Feira de Santana. Feira de Santana, BA, Brasil. 35 pp.

Pollard, S. D.; Beck, M. W. \& Dodson, G. N. 1995. Why do male crab spiders drink nectar? Animal Behaviour 49:1443-1448.

Rosumek, F. B. 2008. Associação de Eremanthus erythropappus (DC.) McLeish (Asteraceae) com formigas e sua relação com a mirmecofauna do solo em floresta de altitude, região central de Minas Gerais. Lundiana 9 (1):41 - 47.

RoubiK, D. W. 1989. Ecology and natural history of tropical bees. 1a. ed. Cambridge: Cambridge University Press. 514 pp.

SANTOS, J. C. \& K. Del-Claro. 2001. Interação entre formigas, herbívoros e nectários extraflorais em Tocoyena formosa (Cham. \& Schlechtd.) K. Schum. (Rubiaceae) na vegetação do cerrado. Revista Brasileira de Zoociências 3 (1): 77-92.

Schoereder, J. H.; T. G. Sobrinho; M. S. Madureira; C. R. Ribas \& P. S. OliveIRA. 2010. The arboreal ant community visiting extrafloral nectaries in the Neotropical cerrado savanna. Terrestrial Arthropod Reviews 3: 3-27.

Schultz, T. R. \& T. P. Mcglynn. 2000. The interactions of ants with other organisms, pp. 35-44. In: Ants: standard methods for measuring and monitoring biodiversity (Agosti, D.; MAJER, J. D.; Alonso, L. E. \& Schultz, T. R. Eds.). Smithsonian Institution Press, Washington.

Silvestre, R.; C. R. F. BRandão \& R. R. Silva. 2003. Grupos funcionales de hormigas: el caso de los gremios del Cerrado. p.113-148. In: FERnÁndez, F. (ed.) Introducción a las hormigas de la Región Neotropical. Smithsonian Institution Press, 398 pp.

TAYLoR, R. M \& R. S. Pfannenstiel. 2008. Nectar feeding by wandering spiders on cotton plants. Environmental Entomology 37: 996-1002.

Thomazini, M. J. \& A. P. B. W. Thomazini. 2002. Diversidade de abelhas (Hymenoptera: Apoidea) em inflorescências de Piper hispidinervum (C. DC.). Neotropical Entomology 31 (1): 27-34. 
Viana, B. F. \& A. M. P. KLeINERT. 2005. A community of flower-visiting bees (Hymenoptera: Apoidea) in the coastal sand dunes of Northeastern Brazil. Biota Neotropica 5 (2): 1-13.

Vilhena-Potiguara, R. C.; A. C. A. Aguiar-Dias; T. Y. S.Kikuchi; A. C. F. Santos \& R. J. F. Silva. 2012. Estruturas secretoras em cipód'alho (Mansoa standleyi (Steyerm.) A. H. Gentry, Bignoniaceae): ocorrência e morfologia. Acta Amazônica 42 (3): .321-328.

Zimmermann, J. G. 1932. Über die extrafloralen nektarien der angiospermen. Beihefte Botanisches Zentralblatt 49: 99-196.

Zorzenon, F. J.; A. E. C. CAmpos; J. Justi JR. \& M. R. Potenza. 2011. Principais pragas da arborização urbana II: formigas carpinteiras. Arquivos do Instituto Biológico (166). <http://www.biologico.sp. gov.br/artigos_ok.php?id_artigo=166>

Recebido em 6 de agosto de 2015 